\title{
A Test to Measure Commercial Dairy Farmer's Knowledge towards Brucellosis in Dairy Animals
}

\author{
A.P. Verma ${ }^{1}$, H.R. Meena ${ }^{2}$, M.N. Sawant ${ }^{3}$ and Archana Bhatt ${ }^{3}$ \\ ${ }^{1}$ Krishi Vigyan Kendra, Bharari, Jhansi-284003 (Uttar Pradesh), India \\ ${ }^{2}$ ICAR-National Dairy Research Institute, Karnal-132001 (Haryana), India \\ ${ }^{3}$ Bombay Veterinary College, (MAFSU) Parel, Mumbai -12, India \\ *Corresponding author
}

\section{A B S T R A C T}

Keywords

Knowledge test,

Brucellosis,

Commercial Dairy

Farmers

Article Info

Accepted:

07 January 2019

Available Online:

10 February 2019
A standardized knowledge test was developed to measure the extent of knowledge of commercial dairy farmers towards brucellosis in dairy animals. Initially 32 items list was prepared which were related to different aspects of brucellosis and its sign, symptoms, modes of transmission, vaccination and prevention and control in dairy animals were selected with discussion of expertsin the field of Veterinary Extension Education, Extension Education, and were from various Agricultural and Veterinary Universities. It was further processed by pretesting and item analysis with using difficulty and discrimination index, as based on the result obtained after calculation some of the items excluded for next step and those items which satisfied the given standard criteria such items are again subjected to point bi serial correlation and finally items which shows the significance value were retained for the final test so in total 20 items were selected for the final Knowledge test.

\section{Introduction}

Brucellosis is a highly contagious, zoonotic and economically important bacterial disease of animals throughout the world and it is considered as one of the most widespread zoonotic disease in the world after rabies. The disease in dairy animals usually caused by Brucella abortus and characterised by abortion in last trimester of pregnancy, infertility and reduced milk yield. Aborted foetuses and discharges contain large number of infectious bacteria and transmit the disease within and in between herds. In addition, chronically infected dairy animals can shed lower numbers of organisms via milk and reproductive tract discharges, and can also vertically transmit infection to subsequently born calves, and maintain disease transmission (McDermott and Arimi 2002). Brucellosis is prevalent in all domestic animals in all states of India with wide variation from as low as 0.13 per cent to as high as 44.00 per cent (Yadav et al., 2012). It has been estimated that the true incidence of disease may be twenty five times higher than 
the reported incidence due to its misdiagnosis and underreporting. Serological study indicates the high rate of Brucellosis on dairy farms in Haryana and Punjab with an overall herd prevalence of 65.54 per cent. It's statewise herd prevalence was 62.79 per cent in Haryana and 72.72 per cent in Punjab (Chand and Chhabra, 2013). The occurrence of the disease is usually high in organized farms compared to the marginal herds and thus predominantly associated with intensive farming practices in large organized animal farms (Smits and Kadri, 2005). In dairy production, this disease is a major impediment to the importation of high yielding breeds and represents a significant constraint to the improvement of milk production through cross breeding. Understanding about brucellosis is therefore vital for strategizing disease control measures. However, such information is inadequate in India. Consequently, appropriate preventive measures have not been undertaken in this part of the world. Therefore, keeping in view of all these aspects, Punjab and Haryana state were selected purposefully and from each state 3 district were selected based on highest cattle population. From each district 20 commercial dairy farmers, thus total 120 commercial dairy farmers were selected based on snowball sampling method. Till date very few studies have been done on the development of knowledge test towards brucellosis especially about commercial dairy farmers, as of now no any standardized knowledge test in India to measure the commercial dairy farmers knowledge towards brucellosis. The present study is an attempt in that way.

\section{Materials and Methods}

The study were conducted in Haryana and Punjab state which was purposively selected because of high rate of Brucellosis prevalence on dairy farms in Haryana and Punjab state were reported with an overall herd prevalence of 65.54 per cent. Three districts were selected from each state based on highest cattle population. From each districts twenty commercial dairy farmers have been selected based on snowball sampling method. Criteria for selection of respondents are that they possess at least 25 dairy animals. Thus, total 120 commercial dairy farmers spread over in six districts constituted the sample for the study.The following steps were followed in development of knowledge test.

\section{Collection of Items}

The content of the knowledge test is composed of questions called items. Items for the test were collected from different sources, such as by reviewing literature, field extension personnel, SMSs, VOs, and Scientist in ICAR-NDRI, Karnal on Brucellosis. The questions were designed to test the knowledge level of Commercial dairy farmers about Brucellosis in Dairy animals. The suitability and applicability of these knowledge test items in the study areas was further validated by experts. Also, every effort was made to see that the sentences were easily understood, simple and each had only one idea. The selection of items was done on the basis of the following criteria:

1. It should promote thinking

2. It should differentiate the well informed commercial dairy farmers from the poorly informed ones on Brucellosis.

3. It should have certain difficulty value.

The procedure followed in selection of the test items was on the lines used by Lindquist (1951), (1965) and Moulik (1965), Based on these criteria, a total of 32 items related to Brucellosis were initially constructed (Appendix-VIII) to form the initial test battery to carry out items analysis for the development of standardized knowledge test. 
The items were of objective type, dichotomous and multiple choice types. This was done to facilitate scoring more easily and objectively.

\section{Pre testing and Item Analysis}

Guilford (1954) pointed out that item analysis of a test usually yields two kinds of information. It provides an index of item difficulty and an index of item discrimination. The item difficulty tells us how difficult an item is, whereas, the index of item discrimination indicates how well the item discriminates in agreement with the rest of the scale or how well it predicts some external criterion. The preliminary knowledge test consisting of 32 items/statements was administered to 30 commercial dairy farmers. A score of 1 was accorded to correct answers and 0 to incorrect answer. Then the total score of each, respondent was calculated by summing of their score for all the items. All these responses were subjected to difficulty index, discrimination index and point-bi-serial correlation.

\section{Item difficulty index}

The difficulty (p-value) of an item is defined as the proportion of commercial dairy farmers who answer the item correctly. The correct response option for an item should be chosen more frequently by the respondents than the incorrect options. Difficult items will have a lower p-value.

The difficulty index of an item or question varied from one respondent to another respondent. The index was calculated for each of the 32 item by dividing total correct responses for a particular item by total number of respondents as given in the formula here;

$\mathrm{Pi}=\frac{n i}{N i} X 100$
Where, $\mathrm{Pi}=$ Difficulty index in percentage of $\mathrm{i}^{\text {th }}$ item $\mathrm{ni}=$ Number of commercial dairy farmers giving correct answers to $i^{\text {th }}$ item $\mathrm{Ni}=$ Total number of commercial dairy farmers to whom $i^{\text {th }}$ item was administered

On the basis of above criteria, the below mentioned items with extreme item difficulty percentages were discarded from the test. The cutting points arbitrarily chosen were 40 and 10 for high and low scores respectively. The remaining 32 items with moderate difficulty percentages were however, retained in the test and were subjected to item discrimination test.

\section{Item discrimination index}

If a statement is answered correctly by every respondents or none in the sample, then it has no discrimination power, whereas, if a statement is answered by some respondents correctly and not by others, such statement has greater power to discriminate the more knowledgeable from the less one.

Hence, only those statements having higher degree of discrimination with respect to varying knowledge level of the respondents were considered for final selection. The discrimination indices of all the 32 raw items were worked out by the following procedure.

At the first, the respondents were arranged and listed in descending order on the basis of their performance in the whole test, out of this list. Top 25 per cent and bottom 25 per cent of the respondents were considered as high and low groups respectively.

Then for each item or question, the number of respondents in the high and low groups who answered it correctly was counted. Finally, the discrimination index (Di) was calculated for each item by using following formula. 
$\mathrm{Di}=\frac{N H-N L}{n} X 100$

Where,

$\mathrm{Di}=$ Discrimination index

$\mathrm{NH}=$ Number of non-sample respondents in top 25 per cent or high groups who answered correctly

NL $=$ Number of non-sample respondents in bottom 25 per cent low groups.

$\mathrm{n}=$ Total number of non-respondents

\section{Point-bi-serial correlation}

Point-bi-serial correlation was worked out to check the internal consistency of selected items.

In other words, the validity power of item was computed by the correlation of the individual item of the whole test.

The point-bi-serial correlation for each of the item of preliminary knowledge test was calculated by using the formula suggested by Garrett (1981).

rpbis $=\frac{M p-M q}{S D * p q}$

Where,

rpbis $=$ Point-bi-serial correlation

$\mathrm{Mp}=$ Mean of the total score of the nonsample respondents, who answered particular item correctly

$\mathrm{Mq}=$ Mean of the total score of the nonsample respondents, who, answered the same item incorrectly

$\mathrm{SD}=$ Standard deviation of the entire sample

$\mathrm{p}=$ Proportion of the respondents who answered correctly to the same item.

$\mathrm{q}=$ Proportion of the respondents who answered incorrectly to the same item.

The calculated point-bi-serial correlation was statistically tested with the help of the table for (n-2) degree of freedom.

\section{Final selection of items for test}

Two criteria were considered for selection of items in the final format of the knowledge test viz. item difficulty and item discrimination index. Those, items, which met the following conditions, were finally selected for the knowledge test based on the following criteria;

1. Item having Difficult index (Pi) between 0.25 to 0.75

2. Item having Discrimination index (di) above 0.20

3. Point-bi-serial correlation coefficient at 5 per cent level of significance.

Overall 20 items were selected for the final test on the basis of above criteria on Brucellosis in Dairy animals.

\section{Results and Discussion}

Total of 20 items were selected for the final knowledge test. Final selected items were putted in the question form to the respondents to obtain the response.

The answer elicited from the commercial dairy were quantified by assigning one score for each correct answer and zero to wrong answer, the score of all the individual items which were answered correctly by respondents were summed up to get the knowledge score of the respondents. The maximum score a respondent could obtain is 40 and minimum score is 0 with respect to knowledge items on brucellosis.

Some of the items were rejected after the calculation of difficulty index and discrimination index, these statement were falling in difficulty index more than 0.75 and discrimination index less than 0.20. So these items were excluded for the further analysis those items are as follows. 


\section{Rejected items after analysis}

1. The factor responsible for increasing incidence of brucellosis in animals is?

a) Yes b)No

2. Do you know that eating of raw and infected milk products is a source of brucellosis?

a) Yes b) No

3. Do you know where brucellosis first recognized as a human disease?

a) Yes b) No

4. Do you know different strain of brucellosis causing disease in different animals?

a) $\quad$ Yes b) No

5. Do you know trade name of brucella vaccines manufactured by Indian Immunological Ltd. (India)?

a) Yes b) No

6. Do you know that direct sunlight harmful to brucella vaccine?

a) Yes b) No

7. Do you know how much (in \%) of animals are protected completely from the most kind of exposure due to vaccine?

a) Yes b)

8. Do you know about method of brucellosis diagnosis in dairy animals?

a) Yes b) No

9. Do you know any government program to eradicate brucellosis in India?

a) Yes b) No

10. Have you any idea about immunity period of brucella vaccine in dairy animals?

a) $\quad$ Yes b) No

11. Do you know about treatment of brucellosis in humans being?

a) $\quad$ Yes b) No

12. Do you know different alternative name of brucellosis?

a) Yes b) No 
The Point-Bi serial (rpb) values of the 20 items retained in the knowledge test

\begin{tabular}{|c|c|c|}
\hline Sl. No. & Statements & rpv value \\
\hline 1. & Have you heard of a disease called Brucellosis? & $\begin{array}{l}0.20 \\
\mathrm{P}<0.1\end{array}$ \\
\hline 2. & What is the causative agent of brucellosis? & $\begin{array}{l}0.25 \\
\mathrm{P}<0.05\end{array}$ \\
\hline 3. & Do you know the type of animals mostly affected by brucellosis? & $\begin{array}{l}0.27 \\
\mathrm{P}<0.05\end{array}$ \\
\hline 4. & $\begin{array}{l}\text { Do you know the most affected sex in dairy animal due to } \\
\text { brucellosis? }\end{array}$ & $\begin{array}{l}0.42 \\
\mathrm{P}<0.001\end{array}$ \\
\hline 5. & Have you experienced abortion in your dairy animals? & $\begin{array}{l}0.19 \\
\mathrm{P}<0.1\end{array}$ \\
\hline 6. & $\begin{array}{l}\text { Do you know the symptoms occurring due to Brucellosis in dairy } \\
\text { animals? }\end{array}$ & $\begin{array}{l}0.18 \\
\mathrm{P}<0.1\end{array}$ \\
\hline 7. & $\begin{array}{l}\text { When an animal fetus is delivered dead at } 6-8 \text { months of pregnancy } \\
\text { indicates? }\end{array}$ & $\begin{array}{l}0.24 \\
P<0.05\end{array}$ \\
\hline 8. & Have you heard about human brucellosis? & $\begin{array}{l}0.28 \\
\mathrm{P}<0.05\end{array}$ \\
\hline 9. & Do you know the symptoms of Brucellosis in human being? & $\begin{array}{l}0.18 \\
\mathrm{P}<0.01\end{array}$ \\
\hline 10. & Do you know stillborn or weak calves born due to brucellosis? & $\begin{array}{l}0.20 \\
\mathrm{P}<0.1\end{array}$ \\
\hline 11. & $\begin{array}{l}\text { Do you know the mode of transmission of Brucellosis in dairy } \\
\text { animals? }\end{array}$ & $\begin{array}{l}0.21 \\
\mathrm{P}<0.1\end{array}$ \\
\hline 12. & $\begin{array}{l}\text { Do you know the mode of transmission of brucellosis to human } \\
\text { being?? }\end{array}$ & $\begin{array}{l}0.31 \\
\mathrm{P}<0.05\end{array}$ \\
\hline 13. & $\begin{array}{l}\text { Do you know AI is the means of brucella transmission in dairy } \\
\text { animals? }\end{array}$ & $\begin{array}{l}0.32 \\
\mathrm{P}<0.05\end{array}$ \\
\hline 14. & The Methods of Prevention of brucellosis in dairy animals is? & $\begin{array}{l}0.27 \\
\mathrm{P}<0.05\end{array}$ \\
\hline 15. & $\begin{array}{l}\text { What precautions should be taken against brucellosis in dairy } \\
\text { animals? }\end{array}$ & $\begin{array}{l}0.17 \\
\mathrm{P}<0.01\end{array}$ \\
\hline 16. & $\begin{array}{l}\text { Do you know that intensive dairy farming will affect the infection of } \\
\text { brucellosis in farm animals? }\end{array}$ & $\begin{array}{l}0.29 \\
\mathrm{P}<0.01\end{array}$ \\
\hline 17. & $\begin{array}{l}\text { Do you know about Methods of Prevention of brucellosis in humans } \\
\text { being? }\end{array}$ & $\begin{array}{l}0.23 \\
\mathrm{P}<0.05\end{array}$ \\
\hline 18. & Do you know vaccine for brucellosis in dairy animals? & $\begin{array}{l}0.20 \\
\mathrm{P}<0.1\end{array}$ \\
\hline 19. & $\begin{array}{l}\text { Which among following vaccine mostly used for brucellosis } \\
\text { treatment in dairy animals? }\end{array}$ & $\begin{array}{l}0.19 \\
\mathrm{P}<0.1\end{array}$ \\
\hline 20. & $\begin{array}{l}\text { What is the right age of vaccination of farm animal against } \\
\text { brucellosis? }\end{array}$ & $\begin{array}{l}0.25 \\
\mathrm{P}<0.05\end{array}$ \\
\hline
\end{tabular}




\section{Items retained for final knowledge test with options}

1. Have you heard of a disease called Brucellosis?

a) Yes b) No

2. What is the causative agent of brucellosis?

a) Bacteria b) Virus c) Fungi d) Don't know

3. Do you know the type of animals mostly affected by brucellosis?

a) Cow b) Buffalo c) Don't know

4. Do you know the most affected sex in dairy animal due to brucellosis?

a) Male b) Female c) Don't know

5. Have you experienced abortion in your dairy animals?

a) Yes b) No

6. Symptoms occurring due to Brucellosis in dairy animals are?

a) Abortion in last trimester of regency b) Retained placenta c) Hygroma/Swollen Joints

d) Swelling of testicle in male) Don't know

7. When an animal fetus is delivered dead at 6-8 months of pregnancy indicates?

a) Brucellosis b) Salmonellosis c) Don't know

8. Do you heard about human brucellosis?

a) Yes b) No

9. Do you know the symptoms of Brucellosis in human being?

a) Fever and arthritis b) Joint and Muscle pains/Night sweat c) Miscarriage in women/Nausea, Fatigue, Skin lesions d) Painful scrotum in men/Headache e) Don't know

10. Do you know stillborn or weak calves born due to brucellosis?

a) Yes b) No

11. Do you know the mode of transmission of brucellosis in dairy animals?

a) Mating with infected animals b) Direct mixing of purchased animal c) Direct contact with infected animals d) Licking of infected placenta e) Don't know

12. Do you know the mode of transmission of brucellosis to human being??

a) Consumption of unpasteurized milk and milk product b) Consumption of contaminated meat

c) During assisting in the parturition of infected animals d) Contact with aborted foetus or foetal membranes e) Don't know

13. Do you know artificial insemination the main method of servicing the cows serve as a means of brucella transmission?

a) Yes b) No

14. The Methods of Prevention of brucellosis in dairy animals is?

a) Vaccination of mature female calf/heifer b) Isolation of infected animals c) Test infected animals before mating and AI d) Don't know

15. What precautions should be taken against brucellosis in dairy animals?

a) Brucellosis testing on a regular basis b) Avoid buying or selling cattle from infected herds c) Bio-security measures e) Don't know

16. Do you know that intensive dairy farming will affect the infection of brucellosis in farm animals?

a) Yes b) No

17. Do you know about Methods of Prevention of brucellosis in humans being?

a) Eating cooked meat and milk product b) Wear gloves during handling the animal's birth c) Wear special work clothes in disposal of placenta d) Safety measures in high work place e) Don't 
know

18. Do you know vaccine for brucellosis in dairy animals?

a) Yes b) No

19. Which among following vaccine mostly used for brucellosis treatment in dairy animals?

a) Brucella abortus strain 19 (S 19)/Brucella Strain RB 51 b) No

20. What is the right age of vaccination of farm animal against brucellosis? a) 4-6 month b) No

The findings of the study revealed that all the questions included in the knowledge test in order to find out the knowledge of the respondents, without standardizing the knowledge test does not give the statistically correct knowledge score of the respondents. It implies that the knowledge test must be standardized as discussed in the present study and which can be used to further in measurement of extent of knowledge of commercial dairy farmers towards brucellosis for accuracy of results. Knowledge test would be great impetus to study the dairy farmers Knowledge level irrespective of the regions and eventually useful for initiating intervention at field level.

\section{References}

Chand, P. and Chhabra, R. (2013). Herd and individual animal prevalence of bovine brucellosis with associated risk factors on dairy farms in Haryana and Punjab in India. Trop Anim Health Prod.,45: 1313-1319.

Guilford, J. P. (1954). Psychometric Methods; Mc Graw Hill, New York.

Garrett, E. and Woodworth, R.S. (1969). Statistics in psychology and education.
Bombay: Vakils Feffer and Simons private Limited. Pp: 329

Lindquist, E. F. (1951). Educational Measurement; American Council on Education, Washington, D.C.

Moulik, T. K. (1965). A study of the predictive values of some factors of adoption of Nitrogenous fertilizers and the influence of source of information on adoption behavior. Ph. D. Thesis Indian Agricultural Research Institute, New Delhi.

McDermott, J. J., and Arimi, S. M. (2002). Brucellosis in sub- Saharan Africa: epidemiology, control and impact. Vet. Microbiol., 90 (1-4): 111-134.

Parameswaranaik, J., R. Senthil Kumar and Verma, A.P. (2017). A Test to Measure Dairy farmers' Knowledge towards Climate Variability. Int.J.Curr.Microbiol.App.Sci. 6 (11): 1254-1260.

Smits, H.L. and Kadri, S.M. (2005). Brucellosis in India: A deceptive infectious disease. Indian Journal of Medical Research, 122: 375-384.

Yadav, M.P., Srivastava, A.K., Prasad, S., Kumaresan A. and Manimaran (2012). Status paper on Brucellosis. Pp. 10.

\section{How to cite this article:}

Verma, A.P., H.R. Meena, M.N. Sawant and Archana Bhatt. 2019. A Test to Measure Commercial Dairy Farmer's Knowledge towards Brucellosis in Dairy Animals. Int.J.Curr.Microbiol.App.Sci. 8(02): 847-854. doi: https://doi.org/10.20546/ijcmas.2019.802.096 